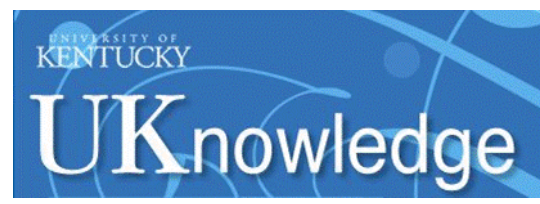

University of Kentucky

UKnowledge

Theses and Dissertations--Kinesiology and Health Promotion

Kinesiology and Health Promotion

2014

\title{
The Effect of Tactical Tasks and Gear on Muscle Activation of SWAT Officers
}

Jason M. Keeler

University of Kentucky, jason.keeler@uky.edu

Right click to open a feedback form in a new tab to let us know how this document benefits you.

\section{Recommended Citation}

Keeler, Jason M., "The Effect of Tactical Tasks and Gear on Muscle Activation of SWAT Officers" (2014). Theses and Dissertations--Kinesiology and Health Promotion. 19.

https://uknowledge.uky.edu/khp_etds/19

This Master's Thesis is brought to you for free and open access by the Kinesiology and Health Promotion at UKnowledge. It has been accepted for inclusion in Theses and Dissertations--Kinesiology and Health Promotion by an authorized administrator of UKnowledge. For more information, please contact UKnowledge@lsv.uky.edu. 


\section{STUDENT AGREEMENT:}

I represent that my thesis or dissertation and abstract are my original work. Proper attribution has been given to all outside sources. I understand that I am solely responsible for obtaining any needed copyright permissions. I have obtained needed written permission statement(s) from the owner(s) of each third-party copyrighted matter to be included in my work, allowing electronic distribution (if such use is not permitted by the fair use doctrine) which will be submitted to UKnowledge as Additional File.

I hereby grant to The University of Kentucky and its agents the irrevocable, non-exclusive, and royalty-free license to archive and make accessible my work in whole or in part in all forms of media, now or hereafter known. I agree that the document mentioned above may be made available immediately for worldwide access unless an embargo applies.

I retain all other ownership rights to the copyright of my work. I also retain the right to use in future works (such as articles or books) all or part of my work. I understand that I am free to register the copyright to my work.

\section{REVIEW, APPROVAL AND ACCEPTANCE}

The document mentioned above has been reviewed and accepted by the student's advisor, on behalf of the advisory committee, and by the Director of Graduate Studies (DGS), on behalf of the program; we verify that this is the final, approved version of the student's thesis including all changes required by the advisory committee. The undersigned agree to abide by the statements above.

Jason M. Keeler, Student

Dr. Mark Abel, Major Professor

Dr. Heather Erwin, Director of Graduate Studies 
THE EFFECT OF TACTICAL TASKS AND GEAR

ON MUSCLE ACTIVATION OF SWAT OFFICERS

THESIS

A thesis submitted in partial fulfillment of the requirements for the degree of

Master of Science in the College of Education at the University of Kentucky

By

Jason M Keeler

Lexington, Kentucky

Advisor: Dr. Mark Abel, Professor of Kinesiology

Lexington, Kentucky

2014

Copyright $\odot$ Jason M Keeler 2014 


\title{
ABSTRACT OF THESIS
}

\section{THE EFFECT OF TACTICAL TASKS AND GEAR ON MUSCLE ACTIVATION OF SWAT OFFICERS}

\begin{abstract}
Special Weapons and Tactics (SWAT) officers constitute a subgroup of specialized law enforcement officers that perform a variety of tactical operations while wearing approximately $40 \mathrm{~kg}$ of tactical gear. Lower back pain is a prevalent musculoskeletal injury suffered by SWAT officers. Tactical gear places significant stress on the lower back. Thus, it is important to quantify the effect that tactical gear has on muscle activation levels of torso musculature while performing occupational tasks. Electromyography was evaluated on 20 male subjects (age: $34.7 \pm 4.5 \mathrm{yr}$; height: $1.79 \pm .10$ m; body mass: $91.53 \pm 17.32 \mathrm{~kg}$; mass of gear: $13.82 \pm 1.90 \mathrm{~kg}$ ) while performing four tactical tasks (standing, rifle walk, sitting, \& shield walk) with and without gear. Electromyography was evaluated bilaterally on the erector spinae, rectus abdominis, and external oblique muscles. The dominant erector spinae (mean delta: $+0.16 \%$ ) and external oblique (mean delta: $-0.124 \%$ ) demonstrated significant changes in muscle activation with the addition of gear, which may indicate increased spinal compression. There were also trends of increased co-activation of core musculature with the addition of gear. The rifle walk and shield walk task mean muscle activations were significantly higher than the standing and sitting tasks. The shield walk produced the highest mean activations for each muscle. Physical training for SWAT officers should emphasize exercises that simulate task-specific movement patterns without gear to decrease the spinal compression associated with load carriage.
\end{abstract}

KEYWORDS: Electromyography, Special Weapons and Tactical Units, Core Musculature, Gait, Muscle Activation 


\title{
THE EFFECT OF TACTICAL TASKS AND GEAR ON MUSCLE ACTIVATION OF SWAT OFFICERS
}

\author{
By
}

Jason M Keeler

Dr. Mark Abel

Director of Thesis

Dr. Heather Erwin

Director of Graduate Studies

August 29, 2014 


\section{ACKNOWLEDGEMENTS}

I would like to thank my thesis advisor, Dr. Mark Abel, for all of his support, time and effort placed in this project. I would also like to thank the rest of my committee members Dr. Mike Pohl, Dr. Rob Shapiro, and Dr. Haley Bergstrom for their time and guidance on this project. I would like to thank all of the friends who helped collect, process and analyze data. Specifically Matt Thomas, Ryan Mason, Michael Baggaley, Jaclyn Norberg, Megan Phillips, Keri Puckett, and Brian Wallace.

In addition to the technical assistant and instrumental assistance above, I wanted to thank my friends and family for emotional support. Most of all, I would like to thank my wife. Your love, support, and motivation helped keep me on track. Lastly, I would like to thank God for giving me the tools to complete such a project, and providing me with the greatest support system. 


\section{TABLE OF CONTENTS}

Acknowledgements.........................................................

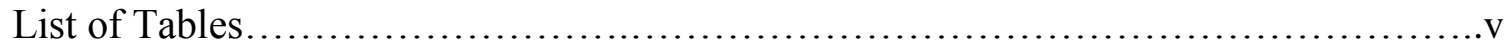

List of Figures...............................................................

\section{CHAPTER I: INTRODUCTION}

Delimitations ............................................................

Assumptions...............................................................

\section{CHAPTER II: REVIEW OF LITERATURE}

Tactical Populations.....................................................4

Electromyography.......................................................

Load Carriage ..............................................................8

Trunk Structure and Function During Gait .................................10

Core Musculature Activation During Load Carriage .............................12

\section{CHAPTER III: METHODOLOGY}

Experimental Approach to the Problem..................................15

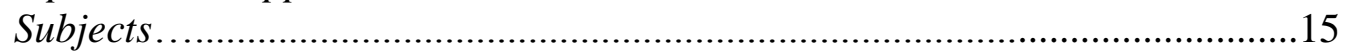

Procedures....................................................... 15

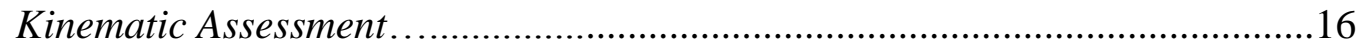

EMG Assessment......................................................16

Statistical Analysis...................................................20

\section{CHAPTER IV: RESULTS}

Mean Muscle Activation: Gear vs. No Gear Condition........................22

Mean Muscle Activation: Between Tasks....................................24

Peak Muscle Activation: Erector Spinae .....................................26

Mean Muscle Activation: Rookies vs. Experienced Officers...................28

\section{CHAPTER V: DISCUSSION}

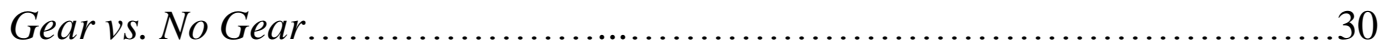

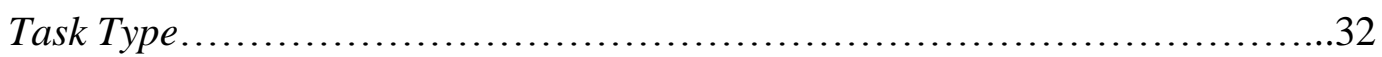

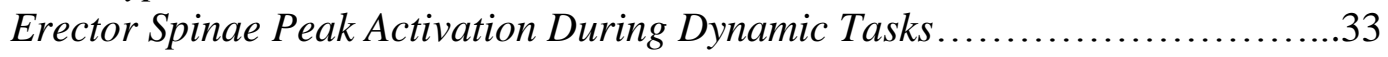

Practical Implications ...................................................... 35

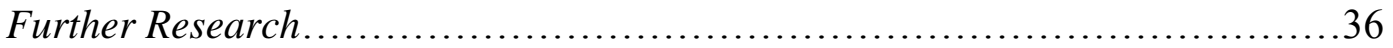

Conclusion........................................................... 37

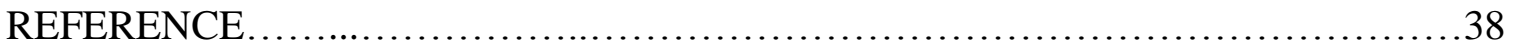

Vita. 


\section{List of Tables}

Table 1, The main effects of muscle activations by gear condition for all tasks in 20

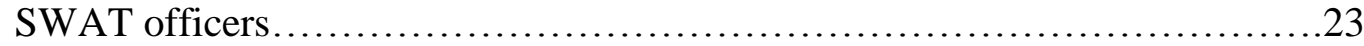

Table 2, Comparison of trunk muscle activation levels by task performed in gear in 20

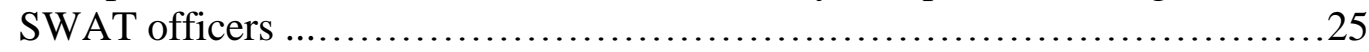

Table 3, Peak bilateral erector spinae muscle activation during dynamic tasks in 20

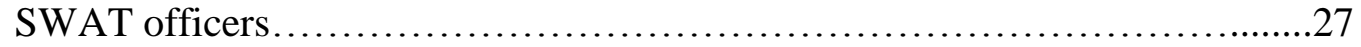

Table 4, Mean muscle activations of experienced ${ }^{t}$ vs. rookie officers during loaded

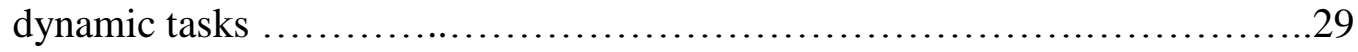


List of Figures

Figure 1, SWAT Tasks......................................................... 


\section{CHAPTER I: INTRODUCTION}

Law enforcement officers (LEO) are responsible for the protection and safety of citizens. Unfortunately, LEOs may incur injuries while performing occupational tasks. Law enforcement officers experience higher injury rates compared to the average work force (19). In fact, the Bureau of Labor Statistics has indicated that injury rates among LEOs are five times greater than most other occupations (19). Regarding injury types, musculoskeletal sprains and strains comprise one-third of all reported hospital injuries in LEOs (33). Nineteen percent of sprains and strains affect the lower trunk (e.g., lower back), and bodily motions alone (i.e., twisting, turning, \& bending without excessive loads other than patrol gear normally worn) cause many of these injuries (33). Furthermore, lower back pain is the most common musculoskeletal injury reported in LEOs (32).

In addition to the high prevalence of lower back injuries reported by LEOs, Special Weapons and Tactics (SWAT) officers constitute a subgroup of specialized LEOs that encounter additional physical requirements. Special Weapons and Tactics officers are elite officers that perform a variety of tactical operations including hostage rescues, counter terrorism operations, subduing barricaded subjects, and engaging criminals. Officers perform these tasks with approximately $40 \mathrm{~kg}$ of tactical gear and equipment including body armor, weapons, ballistic shields, and structural entry tools (31). To safely and effectively perform tactical operations with this equipment officers must maintain sufficient levels of physical fitness. Inadequate physical fitness may increase the relative stress placed on the body, and thus increase the risk of musculoskeletal injury (e.g., back injury or pain (31). To that end, an investigation of a suburban SWAT unit reported that 
$55 \%$ of the officers failed to successfully complete a lower back endurance test, indicating weak lower back musculature (31). This is important because lower levels of muscular endurance have been associated with increased incidence of lower back injuries and pain $(9,29)$.

Given the deleterious personal and financial effects associated with lower back pain and injuries incurred by SWAT officers, it is critical to evaluate the effect SWAT tasks and tactical gear have on the activation levels of torso musculature. This information will provide insight regarding the performance of appropriate ergonomic movements, development of more ergonomically correct equipment, identification of appropriate exercises to strengthen musculature used during tactical tasks, and recommendations regarding loading schedules for various types of officers. Therefore, the primary purpose of this study was to evaluate the effect of $(i)$ tactical equipment and (ii) tasks on the activation of musculature that contributes to spinal stability. The tasks included in this study were: standing, sitting, rifle walk, and shield walk. Our first hypothesis was that the mean muscle activation in the gear trials would be higher than the no gear trials for the same task. Our second hypothesis was that the mean muscle activation would be greatest in the shield walk and rifle walk tasks and least in the standing and sitting tasks, regardless of gear. Given that injuries are associated with lower back dysfunction and weakness, it is beneficial to assess and describe the level of muscle activation while performing tactical tasks.

\section{Delimitations:}

This study is delimited to the following factors. 
1) The sample was a single SWAT unit from a medium sized city in the southeastern United States.

2) Subjects were males aged $25-43$ years with $5.3 \pm 4.2$ years of experience as a SWAT Officer.

Assumptions:

The following assumptions were made for this study.

1) It was assumed that all subjects provided a maximal effort for each physical assessment.

2) It is assumed that body fat did not affect EMG signals. 


\section{CHAPTER II: REVIEW OF LITERATURE}

\section{Tactical Populations}

Tactical populations are a mixture of men and women who perform a myriad of tasks to help protect and serve their country. The broad scope of these populations incorporates people who work in Military, Police, Fire, and Rescue services. This paper focuses on the paramilitary unit within the police service called a Special Weapons and Tactical (SWAT) Unit. There is limited research on this population, so most relevant literature actually comes from military or police studies.

However one study presented by Pryor et al. focused on the fitness characteristics of a SWAT unit. The study mentioned created a needs analysis for a SWAT operator, which noted higher workload demands compared to law enforcement officers (31). This study pointed out that typical tasks included, "trunk rotation, overhead upper extremity use, upper and lower body strength, and long waiting periods followed by explosive movements while wearing additional equipment" (31). One interesting find was that $50 \%$ of the subjects failed a standardized back strength test (31). This finding is important, because with extra load carriage muscular fatigue would occur more quickly. Pryor et al. also stated that limited proximal stability could lead to lumbar injuries, while also causing less efficient movements from the extremities (31). Other studies agree with Pryor et al., suggesting that core musculature enhances performance and injury prevention $(11,13,15,22,29,31)$. Police departments want to decrease injuries, absenteeism, and health care costs, so investigating how torso musculature is activated while performing occupational tasks may assist in designing a more effective fitness regimen (36). 


\section{Electromyography}

Electromyography (EMG) is a commonly used technique to measure muscle activation. The EMG signal is a reflection of the electrical currents produced by the muscle during contraction. This type of investigative technique measures the collective motor unit action potentials within the area of electrode placement. That means muscle fibers outside of the electrode placement area are not measured during the contraction. This is a limitation of electromyography, however this type of testing still allows for a general understanding for what the muscle is doing during contraction.

Electromyography measures the onset and offset of a muscle's electrical activity and allows investigators to understand the complex arrangement of the motor patterns needed to move the body in an efficient manner. Evaluating timing allows a better understanding of how the body must react to perturbations, changes in gait patterns, or other reactions seen in daily activities. The changes in activation patterns could be a sign of an adaption that may benefit or harm the person affected.

Electromyography also measures the magnitude of electrical activity relative to a maximal contraction. Electrical activity does not have a direct linear relationship with force; however there is a relationship that shows that EMG activity increases with force development (10). This investigative technique also requires a reference contraction to compare trials. The reference contraction is usually a maximal voluntary contraction, which is used to compare testing trials. This comparison is called a percent max of maximal voluntary contraction. This form of investigation is at the apex of popularity, 
because it is a simple technique that helps scientist understand what muscles are being utilized to a greater extent during certain tasks.

Electromyography also evaluates the fatigue that occurs within a muscle. Fatigue studies examine the changes in recruitment and firing frequency of the motor unit. As the muscle fatigues the firing rate slowly decreases. This has very good practical application, by giving the investigator a chance to see when the subject is about to reach failure during a contraction. Fatigue is an explanation given for many injuries, so knowing when that may occur could help alleviate some risks for subjects.

There are two main EMG techniques used in the scientific community. The first is surface electromyography, which the electrodes are placed on the skin. The alternate practice of EMG is fine wire indwelling electromyography. Each practice has its own primary purpose in scientific research. Surface electromyography is the noninvasive way to measure muscle activation during muscle contractions. This form of investigation is good for understanding what the muscle as a whole is doing. The broad nature of the electrodes, compared to fine wire, allows for more of the muscle's fibers to be detected during contractions. This detection area allows for universal view of the muscle's activity. On the other hand, indwelling EMG has a more specific application site. This helps reduce crosstalk from other muscles, and it helps in decreasing the extracellular artifact that can be seen in surface electrodes. Each type of electrode is useful for different reasons, however this study focuses on the use of surface electrodes.

Data capture requires analog to digital conversion, along with specialized equipment. The analog-digital conversion must fallow the Nyquist theory, which entails sampling the data at two times the highest frequency. That is at least $1000 \mathrm{~Hz}$ for EMG. 
Most systems use filters to decrease signal noise above $500 \mathrm{~Hz}$ and below $20 \mathrm{~Hz}$ (34). These are prefect for high and low frequencies, however $50-60 \mathrm{~Hz}$ is a problem because that is the frequency range most commonly in other lab equipment (34). Prevention of this influence is possible by notch filtering or the use of differential electrode. Since normal EMG signals fall within that range, differential electrodes would be the preferred choice. Surface EMG uses two types of electrodes, which include differential and double differential electrodes (34). Differential amplification occurs when the signal is sampled at two or more sites with 2-3 electrodes, and then the common signals are subtracted. The remaining signal is amplified (34). Differential amplification helps reduce common signal noise from the detection sites. This creates a much clearer signal, by minimizing the influence of signal noise from sources outside the muscle.

Electromyography requires a variety of processing and analysis techniques to convert a raw signal to a useful piece of information. The first step is omitting the DC offset, by subtracting the mean value of the signal. Then the rest of the processing depends on the goal of the study. The on/off processing can use that raw signal, while the amplitude studies will need more processing. This study focuses on the amplitude of activation; so further processing must be completed. Rectification and smoothing of the signal are needed to obtain a useful mean. This process can be done individually or together using the root mean square smoothing technique. This doesn't involve rectification because of the squared value in the equation (34). The root mean square of the signal represents the signal power, so it is more appropriate by having a physical meaning, according to De Luca (10). After the smoothing and rectification process, general mathematics are used for finding averages and peaks. Numbers usually listed as a 
percent of a maximal voluntary contraction, which could be dynamic or isometric depending on the movement in question. Getting the numbers are fairly easy, but De Luca states that many investigators over interpret or misunderstand the data collected (10).

Interpretation and identification of proper variables, while recognizing the limitation of EMG are vital to good research. First major misconception is the believe EMG and force output are directly related. EMG and force output do not have a direct linear relationship $(10,34)$. There is a general relationship that shows an increase in EMG as force increases. A second limitation for surface EMG is the fact that adipose tissue acts as a low pass filter (34). This diminishes some of the signal that can be seen. Also adipose places the electrode further away from the muscle, so there may be less motor units represented in the signal compared to a thinner subject. These variables can be diminished through the use of normalized numbers that are compared to a maximal voluntary contraction (10). A third limitation of the surface EMG is the movement of the muscle under the surface of the skin (34). This changes the number of motor units under the electrode at different times, which could change the amplitude seen in the signal. Again, use of the reference contraction could help diminish the effect on the signal. Even with these limitations, EMG investigation is still a great tool to understand the general actions occurring within a muscle.

\section{Load Carriage}

Everyone performs carrying a load on his or her body almost every day. The external weight, distance travelled, and many other factors come into play in determining 
how the body must adapt to the excess load. The demands of a job can cause the added weight to be a huge factor in how a task is completed. In a factory the load maybe a box being carried out in front of the body; in a school it could be the excess burden of carrying a backpack with textbooks; but in a tactical mission the load is a mixed bag of weaponry, lifesaving materials, and protective equipment. Major Joseph Knapik provides a review (18) on how load carriage has been looked at in a tactical population. His work along with others has set a basic fundamental groundwork for understanding how load carriage affects the human body.

Most load carriage studies have focused on the physiological and metabolic demands associated with increased loads. Many studies have found that adding a load to the body increases the metabolic demand, by increasing energy expenditure $(17,18,24)$. The increase in energy expenditure can vary based on a number of factors that include load placement, size, and distribution on the body. Knapik's research found placement of the load on the head to be the most efficient placement of load carriage (18). The head placement is most effective, because the center of mass stays within the body. This may be useful information for the civilians carrying items, but a soldier or SWAT officer wears gear to protect the body. A couple of investigations have found an increase in heart rate, oxygen consumption, and rating of perceived exertion during loaded walking or marches $(4,18,24)$. Most of these studies used backpacks or rucksacks. To the best of our knowledge, no research has evaluated SWAT tactical gear on muscle activation.

A few load carriage studies have look at the biomechanical impacts of load carriage. The main focus of these studies have been on how the application of a load affects ground reaction forces. LaFiadra et al. found that ground reaction forces increase 
proportionately as weight is added to a pack load (20). Birrell et al. agree with LaFiadra's conclusions, but also found ground reaction forces change, as the upper body movements are restricted (6). This study looked at military personnel with rifle carries as well as load carriage. They hypothesized that the increase of mediolateral forces occurred from the decreased ability to have arm swing (6). The increased ground reaction forces are contributors to increased risks of overuse injuries $(6,18,20)$. Another biomechanical factor evaluated in the literature are kinematic variations attributed to load carriage. Specifically, multiple studies demonstrate an increased forward lean with load carriage (18). In addition, increased double leg stance times and decreased single leg stance times are also associated with higher loads (21). Most biomechanical outputs have focused on the kinetics and kinematics of load carriage, with an emphasis of the lower extremities. A few studies have used electromyography to evaluate what is occurring in the limbs, but only one study has looked at the core and load carriage.

\section{Trunk Structure and Function during Gait}

Knowing the aspects of trunk and its functions will help guide the research to better understand how the system works together with the rest of the body. The trunk of the human body is classified as the axial skeleton of the body without the head and neck. This region encompasses vital organs including the heart, lungs, kidneys, and others. The spinal column is the major supporting structure of trunk that also provides the nervous system link between the brain and the rest of the body.(25) The trunk of the human body is also known as the passenger during the locomotive efforts of the body. This passenger term seems to come from the fact that the trunk does not generate energy during gait, 
however the trunk musculature must do work during the gait cycle to maintain an upright posture.

The backbone of the trunk is the spine, which consists of the vertebral column and the spinal cord. A few functions of the vertebral column include protection of the spinal cord, aiding in the vertical posture of the body, and helps in energy transfer between limbs (25). The bony structure of each vertebra plays an important role for each of the listed functions, but the ability of the vertebral column to perform the physiological functions necessary for daily life depends on the core musculature that supports the core stability of a person. The bony and ligamentous structures of the spine are supportive in compressive situations, but are weak during the application of shear or torsional forces (3). This is where the core musculature helps prevent buckling of the vertebra (3).

The muscles act as a guy-wire system to create tension throughout the gait cycle to maintain a vertical posture. Just like a guy-wire system, the muscles of the core tense as needed to offset any large deviations from occurring. The forces generated by the musculature during gait are usually small, but can be greater during a perturbation or during different speeds of gait (1). The systematic tensing allows the body to maintain the upright posture for locomotion (1). The tensing patterns vary based on the primary task of each muscle group.

Core musculature is categorized into two main groups, global stabilizing and local stabilizing muscles. The global muscles are used as compliments to the latter in their stabilization duties. However their primary roles are either generating or preventing movement in the spinal structure $(1,3)$. The local stabilizing muscles are deep muscles that are continually active at low levels regardless of the motions being performed. While 
both the global and local systems are important for stabilization, only the global system will be focused on here. The global stabilization system includes several muscles, like the erector spinae and rectus abdominis. This investigation focused on three global muscle groups to allow the use surface EMG data collection. While other muscles would have been beneficial to the study, most would need indwelling electrodes for proper collection. The technique for indwelling electrodes adds unwarranted risk, discomforts, and costs to the project. The three global muscle groups in this investigation were the erector spinae, rectus abdominis, and external obliques.

\section{Core Musculature Activation During Load Carriage}

Many different researchers have studied core musculature, but most have looked at specific core musculature exercises. These exercises include training or rehabilitation exercises like sit-ups, bridges, and other exercises of that nature. However only a few, studies have looked at the core muscular activation during gait, with even fewer studies looking at load carriage gait. Most EMG gait studies have focused on normal or perturbed gait. Articles that have focused on load carriage have focused on the kinematic, kinetic, and metabolic demands associated with carrying the load. However there have only been a couple of studies looking at core muscle activation during load carriage. The aim of this study is to see how the erector spinae, rectus abdominis, and external obliques are being activated during loaded gait, so a few papers have looked at these muscles in similar situations.

The erector spinae has been studied in a few different papers (1-3). The primary finding by a couple of papers found that the erector spinae is active throughout the gait 
cycle at minimal levels, but it also has a burst of activity just before heel strike of the contralateral foot (1-3). This is similar to the activation patterns of the multifidus, which is a primary stabilizing muscle that is positioned deeper in the torso (1). In a study evaluating walking at different speeds, the mean amplitudes of the erector spinae remained consistent up to $4-5 \mathrm{~km} \cdot \mathrm{h}^{-1}$ but increased slightly above those ambulatory velocities (1). This is equivalent to about $1.11-1.38 \mathrm{~m} \cdot \mathrm{s}^{-1}$, which is about the average walking speed for human locomotion. Officer's movements are to be quick, but controlled to decrease risks of putting themselves or others in harm. Slower movements with more awareness to the surroundings are performed when entering a hostile environment. In a study evaluating load carriage, McGill stated that the erector spinae acts to stabilize the pelvis level to decrease pelvic drop towards the swing leg side (24). The erector spinae displays extra muscle activity during upper limb load carriage to account for the added load (24). This study evaluated the application of a load to one or both hands while upright walking. The study found higher activations when the loads were held in one hand compared to two hands (24). The higher one handed activations even occurred when the load was doubled, but placed into two hands (24). McGill reported one handed load carriage (10kg) erector spinae muscle activation values of $7.9 \%$ MVC for the contralateral side, and 4.4\% MVC for the same side. The SWAT ballistic shield is about $13 \mathrm{~kg}$, so a similar or slightly higher number would be expected. Another study in walking gait shows an increase in fatigued trunk extensor musculature can lead to diminished trunk stiffness (27). The decrease in trunk stiffness could contribute to decreased abilities to alleviate ground reaction forces through the trunk (27). The 
potential increases of muscle activation of the erector spinae warrant the investigation of the effect of load carriage, because increased activation can lead to earlier fatigue.

The rectus abdominis and external oblique have been studied to a lesser extent than the erector spinae, but they are also required to maintain a stiff core throughout gait. The rectus abdominis and external oblique data are sometimes unreliable because of the presence of adipose tissue on top of the muscles. However a few studies show that both muscle groups are active during the entire gait cycle $(1,5,38)$. Anders points out that the rectus abdominis is minimally involved during walking gait at different speeds (1). The external obliques are activated more for rotation of the trunk according to Anders, but White showed that the external obliques were active at 5\% or less of MVIC throughout the stride $(1,38)$. The two previous studies have similar findings to other gait investigations, however McGill's group noted a few differences when load carriage was added. In McGill's study of single verse double arm load carriage the rectus abdominis and external oblique muscle groups were much more active (24). The mean contralateral external oblique activation during one-arm load carriage was $10 \%, 27 \%$, and $47 \%$ of MVIC for loads of $10 \mathrm{~kg}, 20 \mathrm{~kg}$, and $30 \mathrm{~kg}$, respectively (24). The SWAT officer's ballistic shield is about $13 \mathrm{~kg}$, so a value between $10-27 \%$ would be expected. This dramatic increase in activation would demand a high muscle endurance demand to tolerate 30 or more minutes of carrying a ballistic shield through an operation. During this study rectus abdominis activity and external obliques activity on the same side as the load increased with the increased load, but not to the same relative magnitude as the erector spinae. The findings from this study begs the question, are different activation levels present between the types of occupational tasks SWAT officers perform? 


\section{CHAPTER III: METHODOLOGY}

\section{Experimental Approach to the Problem}

This study utilized a quasi-experimental case-control design. The independent variables in this study included the use of tactical equipment and performance of occupational tasks. The dependent variable included EMG outcomes. The order of the trials with and without tactical gear was conducted in a block-randomized manner.

\section{Subjects}

A convenience sample of 20 apparently healthy part-time urban SWAT officers was recruited to participate in this study. Subjects were all Caucasian males aged $34.7 \pm$ 4.5 (mean \pm standard deviation) years. The subjects had $10.0 \pm 4.1$ years of service in the police force and served $5.3 \pm 4.2$ years on the SWAT unit. All subjects were asked to provide written informed consent prior to participation in this study. The University's Institutional Review Board approved the study prior to initiation of the study. Subjects provided written informed consent and completed a Physical Activity ReadinessQuestionnaire (PAR-Q) prior to participating in the study. Any positive responses on the PAR-Q excluded them from participation in the study. Subjects were also asked to complete a personal history questionnaire, which included topics related to physical activity level, professional rank, time on the SWAT unit and on the police force, time spent in military, participation in combat competitions and prior musculoskeletal injuries.

\section{Procedures}

Upon arrival to the lab, subjects were asked to fill out the Oswestry Low Back Disability Questionnaire, to provide a description of the lower back pain disabilities within the sample (6). No subjects were excluded based upon responses to this 
questionnaire (12). According to this questionnaire, all subjects in the study had a zero disability rating. Next, physical characteristics were measured. Height (to the nearest 1 $\mathrm{cm}$ ) and body mass (to the nearest $0.1 \mathrm{~kg}$ ) were measured without shoes using a stadiometer and medical grade balance beam scale (Detecto, Webb City, MO). Kinematic Assessment

Subjects had one reflective marker placed on each joint line bilaterally for the ankle (lateral malleolus), knee (lateral condyle of femur), hip (greater trochanter), shoulder (most lateral part of acromion), elbow (lateral epicondyle of humorous), and wrist (half way between ulnar and radial processes of the wrist). Extra reflective markers were applied to the shoes (toe and heel), ballistic shield (anterior corners), and rifle (tip and butt) when necessary. Markers helped determine gait cycles. Six Eagle and four Raptor Motion Analysis Cameras (Motion Analysis, Santa Rosa, CA) collected kinematic data at a sampling rate of 200 frames per second over the runway. Data were collected and tracked using Cortex software (Motion Analysis, Santa Rosa, CA), and filtered/processed using Visual3D software (C-Motion Inc., Germantown, MD) and Microsoft Excel (Microsoft, Redmond, Washington). Marker data were filtered with a recursive $2^{\text {nd }}$ order Butterworth filter using a cutoff frequency of $10.5 \mathrm{~Hz}$.

\section{EMG Assessment}

Bipolar Delsys surface EMG electrodes (Delsys, Boston, MA) were used. The electrodes were $99.9 \% \mathrm{Ag}$ bars, which are $10 \times 1 \mathrm{~mm}$ in diameter with an interelectrode distance of 10mm. EMG detection utilized differential means, an input impedance of $>10^{15} \Omega / / 0.2 \mathrm{pF}$, a Common Mode Rejection Ratio $(\mathrm{CMRR}) \geq 100 \mathrm{~dB}$, a Signal to Noise Ratio $(\mathrm{SNR}) \leq 1.2 \mu \mathrm{V}$, and a Gain setting of $1 \mathrm{~K}$ or $10 \mathrm{~K} \mathrm{~Hz}$. Sampling was collected at 
$2000 \mathrm{~Hz}$ through a 16 bit A-D board. Data were collected on a computer using Cortex software (Motion Analysis, Santa Rosa, CA) and was processed using Visual3D software (C-Motion Inc., Germantown, MD). Filtering was performed using a $2^{\text {nd }}$ order recursive Butterworth band-pass filter with a bandwidth of $20-500 \mathrm{~Hz}$. A moving RMS window of 50 msec was used to rectify and smooth the EMG signal.

All subjects had electrodes placed bilaterally on the skin following Seniam preparation guidelines for the erector spinae, rectus abdominis, external obliques, and the biceps femoris (14). The electrode placements for the erector spinae (longissimus) followed the Seniam Project guidelines (14), while the placement for the external obliques mimic Behm and colleagues' (5) work, and the rectus abdominis followed Brown and McGill's (7) work. Using the anatomical sites indicated above minimized crosstalk. The electrode wires were taped to the skin to decrease excess noise. Subjects wore sleeveless shirts to prevent movement artifact of armor. Rolled elastic wraps provided protection against movement artifact caused by the officers' armor, by not allowing the armor to compress electrodes into the skin.

The subjects completed 2 sets of four basic SWAT tasks. One set of tasks was performed in tactical gear (vest, duty belt, and helmet) and the other set was performed without tactical gear (i.e., in physical training clothes). The order of the gear and no gear trials was block randomized to prevent bias. Three trials were completed for each dynamic task (walking with rifle; walking with shield) and two minutes of recovery was provided between tasks. Two practice trials were completed prior to experimental trials. EMG and kinematic data were averaged over 3-strides for the rifle and shield walking tasks. The following tasks were performed in sequential order; Standing: The first task 
included standing stationary for $60 \mathrm{~s}$. Rifle Walk: The second task required the subject to hold a mock automatic rifle at the ready and walk $5 \mathrm{~m}$. A $30 \mathrm{~s}$ recovery period was provided between trials. Sitting: The third task required the subject to be seated on a 37 $\mathrm{cm}$ tall wooden box (without a back support) for 2 min. Shield Walk: The last task included the use of a $13 \mathrm{~kg}$ ballistic shield held in the non-dominate hand, and required the subject to walk $5 \mathrm{~m}$ using proper technique (Figure 1) while holding a mock sidearm at the ready position. Each of these trials contained a 30s rest period following completion. 
Figure 1: SWAT Tasks

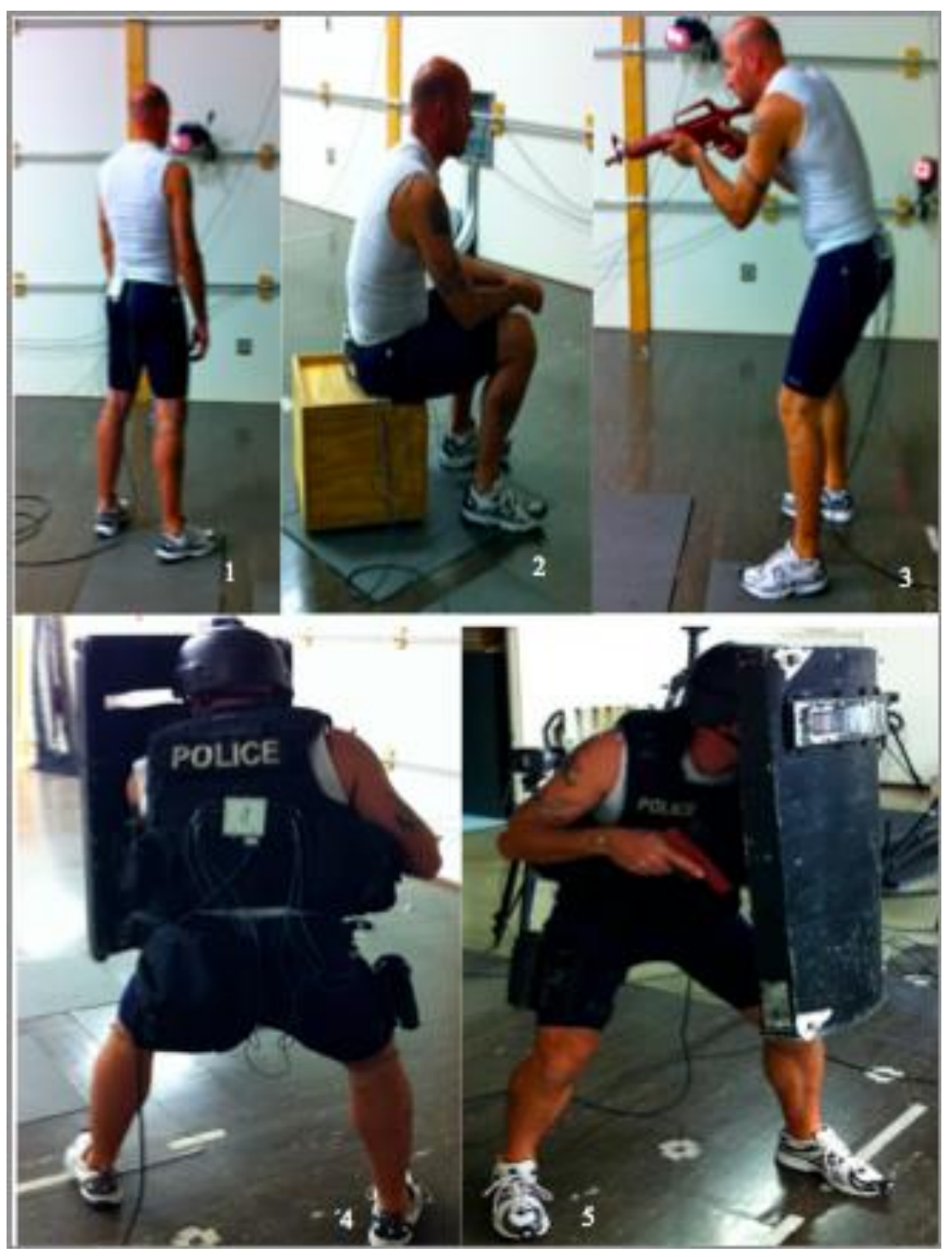

Figure 1. Photos representing the SWAT tasks performed. Note: Although not shown, all tasks were performed with and without gear. Panel 1: Unloaded Standing; Panel 2: Unloaded sitting; Panel 3: Unloaded rifle walk; Panel 4: Loaded shield walk (back); Panel 5: Loaded shield walk (front). 
After the subjects completed testing trials, they were asked to perform a set of maximal voluntary isometric contractions (MVIC). These contractions provided a reference for normalizing the EMG data. The erector spinae muscles were normalized to a modified Biering-Sørensen maximum isometric back extension posture $(5,30)$. For this test, the subject's ankles were secured to the padded table and manual resistance was applied to the subject's thoracic spine so that the back did not extend pass a neutral position. The external oblique activity was normalized to a rotating curl-up MVIC with the application of manual resistance $(5,16)$. The body was allowed to move upwards until the inferior process of the scapula of the rotating side cleared the table. Knees were bent at $90^{\circ}$ with feet held down. The rectus abdominis activity was normalized to a curlup MVIC that was manually resisted at the shoulders. Resistance occurred when both inferior processes of the scapula left the table. Each MVIC lasted for $5 \mathrm{~s}$ with a $30 \mathrm{~s}$ rest period, and the contractions were performed 2 times. Peak values were calculated as the average of the two peak $50 \mathrm{msec}$ periods found during the MVIC trials (one peak from each trial). For all MVIC movements verbal encouragement and instruction were given throughout the trial.

\section{Statistical Analysis}

All reported values are presented as percentages of MVICs for normalization purposes. The average RMS mean was calculated across trials for each task. The averaged RMS means were compared between tasks and between gear versus no gear conditions. An analysis of the kinematic data was not performed, but used to identify gait cycles. Muscles were broken down into dominant and non-dominate groups, so right and left-handedness factored little into differences during statistical analysis. The hand that 
held the trigger of the weapons during the dynamic tasks established hand dominance. The dominant side was referred as Dom (muscle name), with non-dominant being referred to as Non-dom (muscle name).

A summary of EMG data is provided with basic descriptive statistics for the RMS means (mean \pm standard error). Two-way repeated measures ANOVA were used to determine the main effects of gear and task on average muscle activation. Also, a twoway repeated measures ANOVA of peak muscle activation between gear and dynamic tasks of the erector spinae muscles were performed to obtain the main effects. The RMS mean EMG activation data were transformed using a natural log to correct for moderate positive skewness. Therefore, the transformed data were only used to find the $\mathrm{p}$-value of the ANOVAs. The level of significance was set at $p<0.05$. Bonferroni post-hoc analyses were used. Cohen's d limits were used to determine effect size $($ small $=.2$, medium $=.5$, large $=.8$ ). An additional observation was made looking at the mean differences for the comparison of rookie and experience officers. However, a statistical analysis was not conducted due to the small sample size of rookie offices. 


\section{Chapter IV: Results}

Mean Muscle Activation: Effect of Gear

Table 1 displays the mean muscle activation based on gear conditions. The dominant erector spinae muscle showed significant increases with the addition of armor. Whereas, the dominant external oblique demonstrated a significant decrease in activation with the addition of the armor. The average activation difference between the two conditions was less than $.3 \%$ of MVIC for these muscles. There were no significant differences in mean muscle activation between the two conditions for other muscles. 
Table 1. Main effects of mean muscle activation by gear condition for all tasks combined in 20 SWAT officers.

\begin{tabular}{|c|c|c|c|c|c|c|c|}
\hline \multirow[t]{2}{*}{ Muscle } & \multicolumn{4}{|c|}{ Condition } & \\
\hline & Witho & ut Gear * & Witl & a Gear * & P-value & $\begin{array}{c}\text { Effect } \\
\text { Size }\end{array}$ & Power \\
\hline Non-dom Erector Spinae & 2.561 & \pm 0.153 & 2.674 & \pm 0.181 & 0.501 & 0.053 & 0.166 \\
\hline Non-dom External Oblique & 2.110 & 0.362 & 2.073 & \pm 0.291 & 0.100 & 0.003 & 0.056 \\
\hline Non-dom Rectus Abdominis & 0.759 & 0.095 & 0.947 & \pm 0.145 & 0.073 & 0.154 & 0.424 \\
\hline Dom Erector Spinae & 2.679 & 0.285 & 2.839 & \pm 0.252 & 0.030 & 0.208 & 0.563 \\
\hline Dom External Oblique & 2.221 & 0.299 & 2.097 & \pm 0.254 & 0.018 & 0.018 & 0.088 \\
\hline Dom Rectus Abdominis & 0.878 & \pm 0.164 & 0.943 & \pm 0.180 & 0.179 & 0.065 & 0.195 \\
\hline
\end{tabular}




\section{Mean Muscle Activation: Effect of task}

Table 2 displays the average muscle activation values for each individual muscle while performing tasks in gear. All muscles demonstrated significantly greater levels of activation in dynamic (walking with shield $\&$ rifle) versus static (sitting $\&$ standing) tasks in collapsed main effects. There were no differences in muscle activation between sitting and standing tasks for any muscle while in gear. The dynamic conditions had significantly varied activation levels when comparing the shield walk to the rifle walk conditions. The shield walk condition had a slightly higher mean activation level at all muscles compared to the rifle walk condition. The mean activation levels were $1.5 \%$ of MVIC difference or less for each muscle. Bilaterally, the erector spinae were the most active muscles in both dynamic trials followed by the external obliques and the least active were the rectus abdominis muscles. 


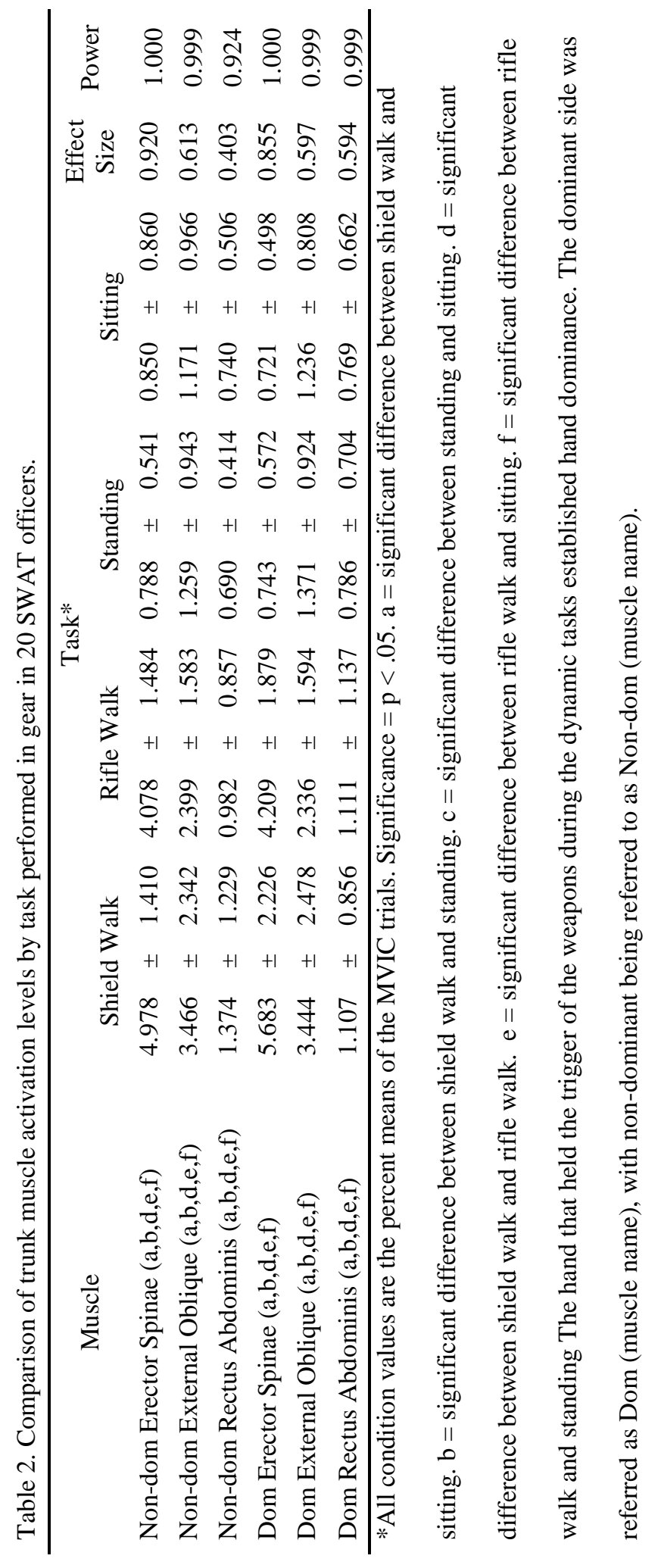




\section{Peak Muscle Activation: Erector Spinae}

The peak activation values for the erector spinae are seen in Table 3. Concurrent analysis of the kinematic data revealed that the erector spinae produced bursts of electrical activity just prior to heel strike. There were significant increases in peak activation values bilaterally during the shield walk compared to the rifle walk while in gear and without gear (Effect of task). There was also a significant increase in peak activation on the dominant erector spinae, while performing both tasks in gear versus out of gear (Effect of gear). 


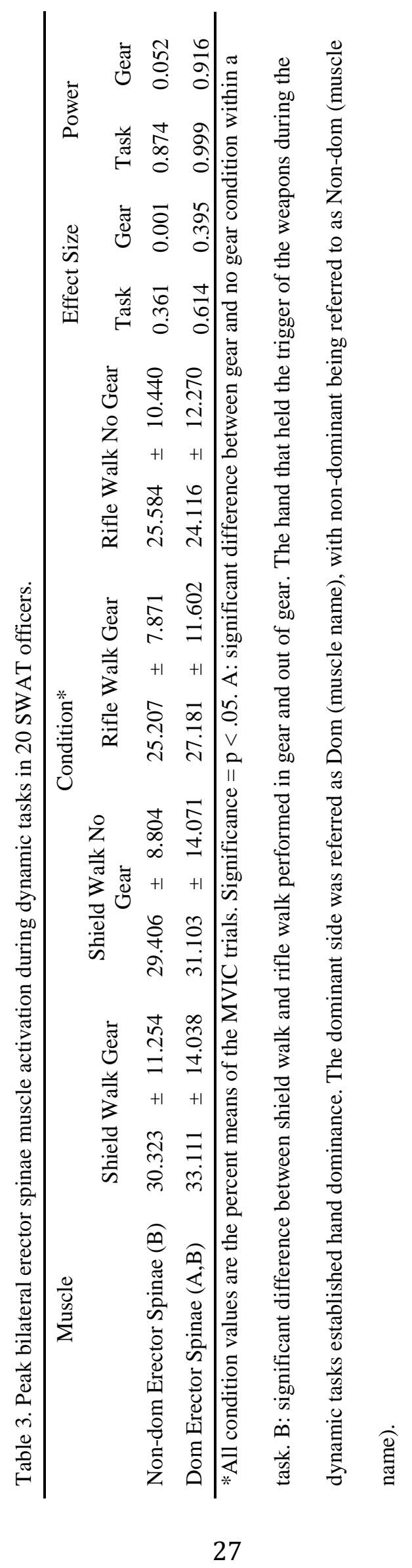


Mean Muscle Activation: Rookies vs. Experienced Officers

The mean muscle activation values of the 18 experienced officers versus the two rookie officers can be seen in Table 4. These data represent performing the dynamic tasks while in gear. The muscle values of both groups are similar in all muscle groups; except there was an increased activation level of the dominant erector spinae for the rifle walk and shield walk tasks. The rookies also had higher total activation levels when all the muscles were added together. Rookies had $15.032 \%$ and $22.433 \%$ total activation, whereas the experienced officers had $15.032 \%$ and $19.787 \%$ total activation for loaded rifle walk and loaded shield walk, respectively. 
Table 4. Mean muscle activations of experienced ${ }^{\mathrm{t}}$ vs. rookie officers during loaded dynamic tasks.

\begin{tabular}{|c|c|c|c|c|c|c|}
\hline & \multicolumn{3}{|c|}{$\begin{array}{l}\text { Experienced Officers } \\
\quad * \quad(\mathrm{n}=18)\end{array}$} & \multicolumn{2}{|c|}{$\begin{array}{l}\text { Rookie Officers } \\
\quad *(n=2)\end{array}$} & $\begin{array}{c}\text { Difference Between } \\
\text { Means }\end{array}$ \\
\hline \multicolumn{7}{|l|}{ Loaded Rifle Walk } \\
\hline Non-dom External Oblique & 2.467 & \pm & 1.632 & 1.762 & 0.443 & -0.705 \\
\hline Non-dom Erector Spinae & 4.069 & \pm & 1.569 & 4.164 & 0.033 & 0.095 \\
\hline Non-dom Rectus Abdominis & 1.057 & \pm & 0.888 & 0.684 & 0.673 & -0.373 \\
\hline Dom External Oblique & 2.249 & \pm & 1.656 & 3.128 & $\pm \quad 0.486$ & 0.879 \\
\hline Dom Erector Spinae & 4.061 & \pm & 1.741 & 5.539 & $\pm \quad 3.410$ & 1.478 \\
\hline Dom Rectus Abdominis & 1.129 & \pm & 1.181 & 0.565 & $\pm \quad 0.471$ & -0.564 \\
\hline Total Mean Activation & 15.032 & & & 15.842 & & 0.810 \\
\hline \multicolumn{7}{|l|}{ Loaded Shield Walk } \\
\hline Non-dom External Oblique & 3.398 & \pm & 2.350 & 4.087 & 3.080 & 0.689 \\
\hline Non-dom Erector Spinae & 5.014 & \pm & 1.481 & 4.655 & 0.500 & -0.359 \\
\hline Non-dom Rectus Abdominis & 1.307 & \pm & 1.213 & 0.983 & 0.900 & -0.324 \\
\hline Dom External Oblique & 3.474 & \pm & 2.615 & 3.178 & 0.506 & -0.295 \\
\hline Dom Erector Spinae & 5.321 & \pm & 1.907 & 8.935 & 2.972 & 3.613 \\
\hline Dom Rectus Abdominis & 1.273 & \pm & 0.978 & 0.595 & 0.433 & -0.678 \\
\hline Total Mean Activation & 19.787 & & & 22.433 & & 2.646 \\
\hline \multicolumn{7}{|c|}{ tExperienced officers: employment less than 1 year with the police department/SWAT team vs. Greater than 1} \\
\hline
\end{tabular}




\section{CHAPTER V: Discussion}

The purpose of this study was to evaluate the effect of tactical gear and occupational tasks on torso muscle activation levels in SWAT officers. The results indicated that tactical gear increased Dom erector spinae muscle activation. Furthermore, there were trends of increased muscle activation for the Non-dom erector spinae and both rectus abdominis muscles. These findings were a little different than what Knapik et al. found with a decrease in erector spinae muscle activation with balanced loads of less than $30-40 \mathrm{~kg}(17)$. The previous study only evaluated a walking task, whereas the present this study asked the operators to use a tactical posture as if entering a hostile situation (i.e., an athletic stance with increased knee and hip/trunk flexion). The different tasks used in each study could explain the discrepant findings. However the slight increases in each muscle's activity may be a sign of increased co-activation of all core musculature, which has been linked to nonspecific low back pain $(3,37)$.

\section{Gearvs. No Gear}

Muscle activity in the core was minimally affected by tactical gear, because of the lack of significant findings. The lack of dramatic changes in muscle activation may be beneficial from a training perspective. Since SWAT gear does not have an appreciable effect on the muscle activation level, this would suggest unloaded training would be beneficial for the development of proper techniques while decreasing the risks of injury caused by gear. Neuromuscular adaptations should be the primary goal for a newer recruit, while refining special weapons and tactics training techniques. McGill stated that correct motor and movement patterns are more important to preventing accumulation of 
trauma to the core (22). This would indicate that technique training and retraining without gear may be the best way to prevent repeated microtrauma from occurring to the spinal column. Meanwhile, the physical stressors needed to enhance the strength, endurance, and stability may be best suited for a more controlled environment like a fitness facility. McGill and colleagues suggested a similar training routine with movement competency components combined with fitness training for a group of firefighters (23). While not training in gear strays from the principal of specificity, occupational movement training may decrease injuries early on, which hopefully may lead to decreased chronic injuries. The total activation levels for the senior officers were lower than the rookies' total activation, which may indicate the implementation of inefficient motor patterns for the less experienced officers. This leads the focus of training back to McGill's belief in occupational movements being utilized during exercise training, which could help the rookies develop proper technique before performing the job tasks in an unfavorable situation with gear.

As for senior officers currently performing SWAT training, it might be best to focus on technique with intermittent loading time or decreased loads. Since load carriage has been associated with injuries, limiting the amount of time in or limiting the weight of the gear during training may decrease injury rates (18). However, there might be some slight drawbacks to how the body could react during a callout, because of the lack of specific training time.

In this investigation, the University's policy would not permit live ammunition in the laboratory, so the load placed on the officers was slightly lighter than a fully outfitted officer. The officers' magazines and extra ammunition were not carried during trials. The 
extra ammunition is normally worn on the front of the vest, which would increase the weight on the anterior portion of the body. The increased anterior weight would shift the center of mass of the upper body slightly forward, which would increase the need for posterior musculature activation to maintain an upright posture (28). This change in muscular assistance should be most prominent in the erector spinae, since this muscle group extends the trunk.

\section{Task Type}

Mean muscle activations differed by task. Specifically, dynamic tasks increased torso muscle activation compared to static tasks. Furthermore, the two static conditions (sitting vs. standing) did not significantly differ for any muscle evaluated. O’Sullivan and colleagues found low levels of activation in all three muscle groups in a study of different sitting and standing postures (26). O'Sullivan et al. found that erect standing and sitting had slightly higher activation levels compared to slumped sitting and slumped standing postures (26). The lower muscle activation in slumped postures occur because more load is placed on the passive structures of the spine, which is believed to lead to strain, instability, or injury (26).

Muscle activation of the dynamic tasks were greater than the static conditions. The values found in this study were very similar to those found in the walking gait trials of other studies. White and colleagues found similar muscle activation levels for the external obliques, rectus abdominis, and erector spinae during walking gait on a treadmill as the present study. They reported mean external obliques activation of less than 3-4\% of MVC, the rectus abdominis averaged less than $2 \%$ of $\mathrm{MVC}$, and erector spinae was 2- 
$3 \%$ of MVC (38). The rifle walk condition in the preset study had relatively close values to White and colleagues (23) walking data. The only difference was slightly higher erector spinae activity in the gear condition of the present study, which could be explained by an increase in forward lean and an increase in height of the subjects' center of mass. Although this study can't definitely say forward lean of the trunk occurred, it has been demonstrated that forward lean increases with load carriage in tactical populations (18). The increase in height of the subjects' center of mass would be inherent in the rifle walk because of the arms being raised to shoulder height and the addition weight of a rifle at the shoulder height. The shield walk task requires a different understanding of what is occurring in the body.

The shield walk condition in the present study produced similar muscle activation values as reported McGill et al. (14), which evaluated load carriage with the arms. McGill et al. reported that single arm (extended at the side) load carriage of $10 \mathrm{~kg}$ and 20 $\mathrm{kg}$ had mean right erector spinae values of $4.4 \%$ and $7.3 \% \mathrm{MVC}$, and the left side had 7.9\% and $13.7 \%$ respectively (24). In the present study, the ballistic shield weighed 13 $\mathrm{kg}$, so the two lower values are close to the activation values seen in this SWAT population. The respective values for the erector spinae muscles would be 5.683\% MVC (compared to $7.9 \%$ ) contralateral to weight, and $4.978 \%$ MVC (compared to 4.4\%) on the weight bearing side. The values in this study may be slightly lower because of how the weight of the shield is carried out in front of the body instead of to the side like McGill's study. Since the center of mass of the shield is more centrally located on the body the erector spinae groups should share the burden of the load more equally. The load can be distributed more evenly for lateral purposes, but in the anterior-posterior directions the 
body must compensate for the center of mass being pulled forward. This fact and the slight increase in weight are likely the reasons why the erector spinae is more active in the shield walk task versus the rifle walk task.

\section{Erector Spinae Peak Activation During Dynamic Tasks}

Research indicates that during walking gait a peak in erector spinae muscle activation occurs just before heel strike of the contralateral foot $(5,24,38)$. The present study found a similar pattern of peak of activation in the erector spinae. White and colleagues noted mean peaks between $15-25 \%$ of MVC, which is comparable to the activation produced by the rifle walking task in the present study (25-27\%) (38). The shield walking task produced an average of over 30\% MVC in the dominant erector spinae and $27-29 \%$ in the non-dominant erector spinae. This increase in muscle activation is normally present during gait to prevent pelvic drop in the frontal plane. The slightly higher peak activation levels noted in the present study may be the body's attempt to counter act the moment created by the shield and rifle at the hip joint. It is important to note that there is substantial variability in muscle activation levels within a given muscle. This variability may be due to the distance at which at which the shield was held from the body.

One major difference in both dynamic tasks compared to either walking study is the position of the officers' body. In the present study officers are in a crouched athletic stance, like a linebacker waiting for a play to start. The other gait studies have people walking in an upright standing posture $(24,38)$. Even the past military load carriage studies looked at rucksack carrying and other load carriage tasks which were performed 
in more upright postures (18). Looking at how the body must adapt to load carriage in the tactical ready positions might be more applicable to this and other tactical populations. The upright walking stance doesn't mimic the needs of callout demands for this population.

There were several limitations to the present study. First, this study utilized a convenience sample, which limits the generalizability of these findings. Second, the EMG data had high variability, which decreased the statistical power to identify true differences. However, the normalized values for the muscles helped decrease differences caused by subject's body fat, but since the adipose acts as a low pass filter some muscle activation were undoubtedly lost. The final major limitation of this study was the inability to use real weapons and ammunition carried during an operation. However the mock weapons used in this study are the identical to those used during training. Lastly, this study only evaluated a short stride interval of three to four strides and short sitting and standing times, which only simulates a small sample of the movements and time needed during SWAT operations.

\section{Practical Applications}

SWAT operators have a variety of training needs to prepare for diverse occupational tasks. Their training needs to focus on equipment use, tactics, and interpersonal interactions (8). Many SWAT units are part-time, so training time is a valuable asset. With that in mind the officers still need to perform physical training to induce positive physiological adaptations to enhance job preparedness. Based on 
observations from this study and literature focused on core musculature a few suggestions can be made.

The literature indicates that increases in co-activation of core musculature leads to greater spinal compression (3). This compression is believed to contribute to the increase of nonspecific low back pain $(3,35)$. The minor increases in muscle activation from the dynamic movements may suggest regular periods of spinal decompression may help limit the amount of time of increased co-activation. With that in mind it would be wise to allow officers breaks in between training sessions to decrease compressive load exposure on the spinal column.

The specificity training principle suggests that fitness training should include exercises that place similar stress on the body as occupational tasks do. The use of functional movements to train the body as a whole should be considered. An example of a functional exercise is the front squat, which may be more applicable because the load is applied on the anterior portion of the torso. This exercise stimulates core musculature while also challenging the triple extension of the hip, knee, and ankle. In addition, Behm and colleagues found moderate to intense running activates core musculature to a greater extent than back extension exercises (5). Thus intense running will enhance cardiovascular fitness and enhance core strength and endurance. Additional exercises to stimulate torso musculature can be found elsewhere (McGill et al.).

\section{Future Research}

This study only looked at a few strides of gait, but SWAT operators are carrying large loads through structures for various distances. A future study may look at how the muscles react after a prolonged time of wearing tactical gear. Looking at how core 
musculature reacts after wearing the gear in prolonged static positions will be vital to future research since officers wear this gear for long periods of time before performing explosive movements. This could be interesting to see how the muscles must react after passive tissues have creped to the point of laxity in the spinal column.

\section{Conclusion}

Overall this study demonstrated that torso muscle activation in gear and out of gear is not significantly different, whereas activation by task is significantly different. The similar findings from previous gait studies, suggests the gear may not be playing a huge role in affecting trunk activation during straight-line gait. However when looking at different tasks it would be beneficial to practice out of gear to gain the neuromuscular adaptations required for the occupational task. The decreased exposure to the compressive nature of the gear may alleviate a contributor to lower back pain. 


\section{REFERENCES}

1. Anders C, Wagner H, Puta C, Grassme R, Petrovitch A, and Scholle H-C. Trunk muscle activation patterns during walking at different speeds. Journal of Electromyography \& Kinesiology 17: 245-252, 2007.

2. Anders C, Wagner H, Puta C, Grassme R, and Scholle HC. Healthy humans use sex-specific co-ordination patterns of trunk muscles during gait. European journal of applied physiology 105: 585-594, 2009.

3. Barr KP, Griggs M, and Cadby T. Lumbar stabilization: core concepts and current literature, part 1. American Journal of Physical Medicine \& Rehabilitation 84: 473-480, 2005.

4. Beekley MD, Alt J, Buckley CM, Duffey M, and Crowder TA. Effects of Heavy Load Carriage during Constant-Speed, Simulated, Road Marching. Military Medicine 172: 592-595, 2007.

5. Behm DG, Cappa D, and Power GA. Trunk muscle activation during moderateand high-intensity running. Applied physiology, nutrition, and metabolism = Physiologie appliquee, nutrition et metabolisme 34: 1008-1016, 2009.

6. Birrell SA, Hooper RH, and Haslam RA. The effect of military load carriage on ground reaction forces. Gait \& posture 26: 611-614, 2007.

7. Brown SH and McGill SM. Co-activation alters the linear versus non-linear impression of the EMG-torque relationship of trunk muscles. Journal of biomechanics 41: 491-497, 2008.

8. Clark JG and Jackson MS. Training SWAT teams Implications for improving tactical units. Journal of Criminal Justice 28: 407, 2000. 
9. Crill MT and Hostler D. Back Strength and Flexibility of EMS Providers in Practicing Prehospital Providers. Journal of Occupational Rehabilitation 15: $105-$ $111,2005$.

10. De Luca CJ. The use of surface electromyography in biomechanics. / Utilisation de 1 ' electromyographie de surface en biomecanique. Journal of Applied Biomechanics 13: 135-163, 1997.

11. Ekstrom R, Donatelli R, and Carp K. Electromyographic Analysis of Core Trunk, Hip, and Thigh Muscles During 9 Rehabilitation Exercises. Journal of Orthopaedic \& Sports Physical Therapy 37: 754-762, 2007.

12. Fairbank JC and Pynsent PB. The Oswestry Disability Index. Spine 25: 29402952, 2000.

13. Hendrickson NR, Sharp MA, Alemany JA, Walker LA, Harman EA, Spiering BA, Hatfield DL, Yamamoto LM, Maresh CM, Kraemer WJ, and Nindl BC. Combined resistance and endurance training improves physical capacity and performance on tactical occupational tasks. European journal of applied physiology 109: 1197-1208, 2010.

14. European Recommendations for Surface Electromyography: Results of the Seniam Project (SENIAM) by Hermie J. Hermens http://seniam.org/. 2013.

15. Iwai K, Nakazato K, Irie K, Fujimoto H, and Nakajima H. Trunk muscle strength and disability level of low back pain in collegiate wrestlers. Medicine \& Science in Sports \& Exercise 36: 1296-1300, 2004. 
16. Karst GM and Willett GM. Effects of specific exercise instructions on abdominal muscle activity during trunk curl exercises. Journal of Orthopaedic \& Sports Physical Therapy 34: 4-12, 2004.

17. Knapik J, Harman E, and Reynolds K. Load carriage using packs: a review of physiological, biomechanical and medical aspects. Applied Ergonomics 27: 207216, 1996.

18. Knapik JJ, Reynolds KL, and Harman E. Soldier Load Carriage: Historical, Physiological, Biomechanical and Medical Aspects. Military Medicine 169: 45$56,2004$.

19. http://www.bls.gov. 2012.

20. Lafiandra M and Harman E. The Distribution of Forces between the Upper and Lower Back during Load Carriage. Medicine \& Science in Sports \& Exercise 36: 460-467, 2004.

21. Lee M, Roan M, and Smith B. An application of principal component analysis for lower body kinematics between loaded and unloaded walking. Journal of biomechanics 42: 2226-2230, 2009.

22. McGill S. Core Training: Evidence Translating to Better Performance and Injury Prevention. Strength \& Conditioning Journal (Lippincott Williams \& Wilkins) 32: 33-46, 2010.

23. McGill S, Frost D, Andersen J, Crosby I, and Gardiner D. Movement quality and links to measures of fitness in firefighters. Work: Journal of Prevention, Assessment \& Rehabilitation 45: 357-366, 2013. 
24. McGill SM, Marshall L, and Andersen J. Low back loads while walking and carrying: Comparing the load carried in one hand or in both hands. Ergonomics 56: 293-302, 2013.

25. O'loughlin VD and McKinley M. Human Anatomy New York, NY: McGraw-Hill, 2006.

26. O'Sullivan PB, Grahamslaw KM, Kendell M, Lapenskie SC, Möller NE, and Richards KV. The effect of different standing and sitting postures on trunk muscle activity in a pain-free population. Spine 27: 1238-1244, 2002.

27. Olson MW. Trunk extensor fatigue influences trunk muscle activities during walking gait. Journal of Electromyography \& Kinesiology 20: 17-24, 2010.

28. Park H, Branson D, Kim S, Warren A, Jacobson B, Petrova A, Peksoz S, and Kamenidis P. Effect of armor and carrying load on body balance and leg muscle function. Gait \& posture 39: 430-435, 2014.

29. Peate WF, Bates G, Lunda K, Francis S, and Bellamy K. Core strength: A new model for injury prediction and prevention. Journal of Occupational Medicine \& Toxicology 2: 3-9, 2007.

30. Pitcher MJ, Behm DG, and MacKinnon SN. Reliability of electromyographic and force measures during prone isometric back extension in subjects with and without low back pain. Applied Physiology, Nutrition \& Metabolism 33: 52-60, 2008.

31. Pryor RR, Colburn D, Crill MT, Hostler DP, and Suyama J. Fitness characteristics of a suburban special weapons and tactics team. Journal Of Strength And 
Conditioning Research / National Strength \& Conditioning Association 26: $752-$ $757,2012$.

32. Ramstrand N and Larsen LB. Musculoskeletal injuries in the workplace: perceptions of Swedish police. International Journal of Police Science \& Management 14: 334-342, 2012.

33. Reichard AA and Jackson LL. Occupational injuries among emergency responders. American journal of industrial medicine 53: 1-11, 2010.

34. Robertson DGE, Caldwell GE, Hamill J, Kamen G, and Whitlesey SN. Research Methods in Biomechanics. Champaign, IL: Human Kinetics, 2004.

35. Solomonow M. Time dependent spine stability: the wise old man and the six blind elephants. Clin Biomech (Bristol, Avon) 26: 219-228, 2011.

36. Spitler DL, Jones G, Hawkins J, and Dudka L. Body composition and physiological characteristics of law enforcement officers. / Composition corporelle et caracteristiques physiologiques des fonctionnaires de police. British journal of sports medicine 21: 154-157, 1987.

37. Toosizadeh N, Nussbaum MA, Bazrgari B, and Madigan ML. Load-Relaxation Properties of the Human Trunk in Response to Prolonged Flexion: Measuring and Modeling the Effect of Flexion Angle. PLoS ONE 7: 1-10, 2012.

38. White SG and McNair PJ. Abdominal and erector spinae muscle activity during gait: the use of cluster analysis to identify patterns of activity. Clinical Biomechanics 17: 177, 2002. 


\section{Vita}

The author, Jason M Keeler, was born in Indianapolis, IN on July $20^{\text {th }}, 1988$ and raised in Fishers, Indiana. He attended Indiana University from 2007-2011, and received a Bachelor of Science in Exercise Science. He began his work towards a Masters of Science in Exercise Physiology at the University of Kentucky in the Fall of 2011. 